\title{
Imobilização prolongada e remobilização da articulação fêmoro-tíbio-patelar de ratos: estudo clínico e microscópico
}

\author{
[Experimental immobilization and remobilization rat knee joints: clinical and microscopic study] \\ R.J. Del Carlo ${ }^{1}$, M.R. Galvão ${ }^{1}$, M.I.V. Viloria ${ }^{1}$, A.J. Natali ${ }^{2}$, A.L.T. Barbosa ${ }^{1}$, \\ B.S. Monteiro ${ }^{1}$, L.C.P. Pinheiro ${ }^{1}$ \\ ${ }^{1}$ Departamento de Veterinária - UFV \\ Av. P.H. Rolfs, $\mathrm{s} / \mathrm{n}$ \\ 36570-000 - Viçosa, MG \\ ${ }^{2}$ Departamento de Educação Física - UFV - Viçosa, MG
}

\begin{abstract}
RESUMO
Trinta e quatro ratos foram alocados em quatro grupos experimentais: sem imobilização (G1), com imobilização do joelho direito por 45 dias (G2), com imobilização e remobilização com atividade livre por cinco semanas (G3), imobilização e remobilização com atividade livre e natação por cinco semanas (G4). A imobilização interferiu negativamente na marcha e amplitude articular e o G4 apresentou melhor evolução na marcha nos cinco primeiros dias, em relação ao G3. Após esse período, a evolução foi similar. Os componentes do G2 apresentaram rigidez articular, não observada em G3 e G4. Histologicamente, a imobilização promoveu aumento da espessura da cápsula articular, evidenciada pela presença do tecido conjuntivo fibroso que substituiu o tecido adiposo no G2, mas em menor proporção em G3 e G4. A imobilização determinou perda de proteoglicanos da matriz cartilaginosa, aumento do número de condrócitos, dispostos de forma irregular, aumento da espessura da cartilagem calcificada, irregularidade da superfície articular, proliferação de tecido conjuntivo no espaço intra-articular e aumento da espessura do osso subcondral. O G3 apresentou maior número de alterações na cartilagem e osso subcondral, quando comparado com G4. A imobilização degenerou as células sinoviais, indicando diminuição da produção de fluido sinovial e do suprimento nutricional à cartilagem. Tanto a atividade livre quanto sua associação com a natação favoreceram o retorno das condições biomecânicas e da cápsula articular, anteriores à imobilização.
\end{abstract}

Palavras-chave: rato, imobilização articular, remobilização articular, artrose

\begin{abstract}
Thirty-four rats were randomly allocated into one of four experimental groups: without immobilization (G1), immobilization of the right knee joint for 45 days (G2), immobilization and remobilization with free activity for 5 weeks (G3), and immobilization and remobilization with free activity and swimming program for 5 weeks (G4). The immobilization was prejudicial to march and flexibility articular. Animals from G4 showed a better march evolution on the first five days as compared to those from G3. After that periods, march evolution were similar in both G3 and G4. Animals from G2 showed rigid joint while in those from G3 and G4 the articular movement was close to normal. The histological analysis pointed out that immobilization led to increase in articular capsule thickness evidenced by the presence of fibrous connective tissue replacing adipose tissue in G2, but proportionally less in G3 and G4. It was observed that immobilization determined loss of proteoglycans from the cartilaginous matrix, increase in the number of regularly arranged condrocytes, increase in calcified cartilage thickness, irregularity in the articular surface, proliferation of connective tissue in the intra-articular space and increase in
\end{abstract}


subchondral bone thickness. The animals from G3 showed a greater number of alterations in both articular cartilage and subchondral bone, as compared to those from G4. Immobilization degenerated synovial cells indicating decreased synovial fluid production and reduced nutritional supplying to the cartilage. The free cage activity and its association with swimming influenced positively the return of biomechanics and articular capsule morphologic conditions to those before immobilization.

Keywords: rat, articular immobilization, articular remobilization, arthrosis

\section{INTRODUÇÃO}

A cartilagem articular requer algum regime de carga e movimento para manter sua natureza física e propriedades bioquímicas. Modelos experimentais, in vivo, de redução de carga articular e imobilização do membro induzem a degeneração articular, incluindo redução da hidratação, alteração da estrutura e redução da síntese de proteoglicanos. A diminuição da espessura da cartilagem pode refletir menor capacidade de absorção de cargas na articulação. Algumas dessas alterações são, ao menos parcialmente, reversíveis para valores normais após a remobilização (Leroux et al., 2001; Narmoneva et al., 2002).

As mudanças histológicas que ocorrem após imobilização de articulação sinovial normal são progressivas e incluem proliferação dos tecidos sinovial e conjuntivo, aderência da superfície articular, necrose e ulceração da cartilagem e alterações do osso subcondral (Thaxter et al., 1965).

Para Brandt (2003), a imobilização prolongada de uma articulação sinovial resulta em perda de macromoléculas estruturais da matriz, porém, se a imobilização for interrompida, os condrócitos voltam a sintetizar as macromoléculas com suficiente rapidez, e a cartilagem poderá ser sintetizada com êxito, tornando as alterações reversíveis. Caso contrário, a lesão poderá ser permanente e irreversível.

Após imobilização da articulação de ratos, as mudanças mais precoces e severas acontecem nas áreas de contato entre superfícies articulares, resultando em rápido início de necrose. As alterações ocorrem tanto por ação da compressão mecânica quanto pela imobilização, por impedir a difusão de nutrientes do fluido sinovial pela cartilagem comprimida. A ausência de movimento articular e conseqüente falta de bombeamento pode também impedir a difusão do fluido sinovial (Roy, 1970).

O objetivo deste trabalho foi avaliar, por meio de observações clínicas e análises microscópicas, sob microscopia de luz, os efeitos da imobilização articular prolongada e da remobilização sobre o joelho de ratos.

\section{MATERIAL E MÉTODOS}

Utilizaram-se 34 ratos adultos machos (Ratus Norvegicus - Wistar), com peso médio de 200 gramas, provenientes do Biotério Central da Universidade Federal de Viçosa, que foram distribuídos aleatoriamente em um dos quatro grupos experimentais: 1) sem imobilização (G1, $n=4)$; 2) com imobilização (G2, $n=10)$; 3 ) imobilização e remobilização com atividade livre (G3, $n=10)$; e 4) imobilização e remobilização com atividade livre e natação (G4, $n=10)$. Os pacientes foram alojados em gaiolas coletivas (dois por gaiola) e mantidos em ambiente com temperatura média de $24^{\circ} \mathrm{C}$ e fotoperíodo de 12 horas. Todos os animais receberam ração comercial e água à vontade.

Os animais dos grupos 2, 3 e 4 foram anestesiados por inalação de éter anestésico em câmara de gás, e a anestesia geral foi mantida em circuito aberto. Posteriormente, tiveram a articulação femorotibiopatelar direita imobilizada com atadura gessada, em posição de extensão, por 45 dias. Para manter a imobilização, a atadura foi colocada ao redor das regiões pélvica e abdominal, mantendo também a articulação coxofemoral em abdução de 45 graus e a região tibiotársica livre, não impedindo o deslocamento dos animais nas gaiolas.

Após a retirada do gesso, os animais do G3 foram mantidos nas gaiolas, movimentando-se livremente durante cinco semanas. Os componentes do G4, após a retirada do gesso, 
além da movimentação livre, foram submetidos a um programa progressivo de natação, cinco dias consecutivos por semana, durante cinco semanas de acordo com o seguinte protocolo: na primeira semana, para adaptação, os animais nadaram por cinco minutos, acrescentando-se cinco minutos por dia a partir do segundo dia. Assim, ao final da primeira semana estavam nadando por 25 minutos. Na segunda semana, iniciou-se com 30 minutos de natação chegando aos 50 . Na terceira semana, iniciou-se com 55 minutos, atingindo 60 no segundo dia. A partir daí, a sessão de natação teve duração diária de 60 minutos até a quinta semana.

A natação foi executada em um tanque com as seguintes dimensões: $80 \mathrm{~cm}$ X $65 \mathrm{~cm}$ X $45 \mathrm{~cm}$ (profundidade, largura e comprimento, respectivamente), com água aquecida e mantida entre 32 e $35^{\circ} \mathrm{C}$. O nível da água inicialmente foi de $19 \mathrm{~cm}$ para que os animais pudessem colocar o membro no fundo do tanque, permitindo melhor adaptação. A partir do segundo dia, foi aumentado para $30 \mathrm{~cm}$, permitindo somente a natação livre.

Para avaliação clínica da marcha, após a retirada da imobilização, os animais do G3 e G4 foram observados em suas respectivas gaiolas cinco dias consecutivos por semana, durante cinco semanas, num total de 25 parcelas de tempo, classificando a evolução da marcha com notas variando de 1 a 5 , de acordo com os seguintes critérios: 1- marcha sem apoio; 2- marcha com apoio do membro mantendo-o em extensão e abdução; 3- marcha com apoio do membro mantendo-o em extensão; 4- marcha com apoio do membro mantendo-o em abdução; 5- marcha normal. Para análise estatística, os dados da avaliação das marchas dos grupos atividade livre (G3) e atividade livre + natação (G4) foram submetidos à análise de variância. Os dados foram, em seguida, submetidos ao teste Tukey a $5 \%$ de probabilidade com resíduo combinado (erro A + erro B) e grau de liberdade combinado, para analisar o comportamento das médias das marchas ao longo do tempo.

Para a avaliação da efetividade da remobilização, nos animais do G2, G3 e G4, analisou-se o grau de movimentação da articulação do joelho em comparação com a movimentação da articulação contralateral, determinando, desta forma, a resistência à flexão articular, de acordo com Evans et al. (1960).

Para análise histológica, foram coletadas a cápsula da articulação femorotibiopatelar e as epífises distal do fêmur e proximal da tíbia direita de todos os animais. As cápsulas foram isoladas após dissecação dos ligamentos patelar e colaterais e liberação da patela. Em seguida, foram fixadas em formol neutro a $10 \%$ tamponado, por aproximadamente 24 horas. Após a fixação, foram processadas rotineiramente pela técnica de inclusão em parafina, e realizados cortes de $6 \mu \mathrm{m}$ de espessura e corados com hematoxilina e eosina (HE), e examinados ao microscópio óptico objetivando analisar a proliferação de tecido conjuntivo subsinovial intracapsular, presença de vilos e proliferação celular.

Os fragmentos osteocondrais coletados foram fixados em formol neutro a $10 \%$ tamponado, por aproximadamente 48 horas. Após a fixação, os fragmentos foram descalcificados em ácido fórmico a 10\%, tamponado com citrato de sódio ( $\mathrm{pH} 4,5)$, sob vácuo moderado. Após descalcificação, foram seccionados longitudinalmente e, então, processados rotineiramente pela técnica de inclusão em parafina. Os cortes de $6 \mu \mathrm{m}$ de espessura foram corados com HE e azul de toluidina e examinados ao microscópio óptico objetivando analisar alterações celulares e da matriz cartilaginosa, proliferação de tecido conjuntivo no espaço intra-articular, irregularidade da superfície articular e a espessura e o aspecto das trabéculas do osso subcondral.

Os achados histológicos foram submetidos à análise descritiva.

\section{RESULTADOS E DISCUSSÃO}

$\mathrm{Na}$ avaliação da marcha, o G4 demonstrou um significativo retorno à normalidade nos cinco primeiros dias em relação ao G3. Após esse período, houve tendência dos grupos apresentarem a mesma evolução em relação ao tempo. A melhora do G4 pode estar relacionada aos efeitos fisiológicos do calor, pelo processo de condução passando da água aquecida para os tecidos, determinando alívio da dor ou aumento do seu limiar, relaxamento muscular, aumento do 
fluxo sanguíneo e a redução da rigidez articular providos pelo aumento da extensibilidade do colágeno, segundo Collins (1998). Provavelmente, também, as atividades realizadas dentro da água motivaram aumento da amplitude articular, fortalecimento dos músculos enfraquecidos, aumento da tolerância aos exercícios, bem como redução de edemas que, segundo Campion (2000), ocorre pela ação da pressão hidrostática.

Segundo o princípio de Arquimedes (Campion, 2000), quando um corpo é submerso em um líquido, ele sofre uma força de flutuabilidade igual ao peso do líquido que desloca, sendo a densidade relativa da água aceita como uma proporção de 1, qualquer objeto com uma densidade menor que 1 irá flutuar. Por essa razão, nos pacientes do $\mathrm{G} 4$, ocorreu alívio do estresse sobre as articulações em estudo, permitindo a realização de movimentos em forças gravitacionais reduzidas e com menor fricção. Pode-se inferir que a natação em piscina aquecida determinou melhora mais rápida da marcha, com o apoio do membro comprometido mais precocemente.

Durante a avaliação da resistência à flexão articular, mediante mensuração direta do grau de movimentação, observou-se, nos animais do G2, além de rigidez articular, atrofia da musculatura, que estava ausente no G3 e G4, após as cinco semanas de remobilização. Com a imobilização, ocorreu ausência de movimento e, conseqüentemente, da contração muscular, ocasionando diminuição do fluxo sangüíneo, edema e hipóxia, que determinaram a hipotrofia muscular, comum nestas situações segundo Salter (1985).

Na avaliação histológica da cápsula articular, observou-se, no G2, espessamento com substituição total do tecido adiposo por tecido conjuntivo fibroso quando comparado ao controle (Fig. 1). No G3, em um animal houve substituição total, porém os outros animais se comportaram como o G4, em que houve espessamento, mas com a substituição parcial do tecido adiposo por tecido conjuntivo fibroso. Infere-se que tanto o exercício livre (G3) quanto o orientado (G4) influenciaram positivamente o retorno das condições morfológicas da cápsula, anteriores à imobilização.
Em todos os pacientes do G2, ocorreu substituição do tecido adiposo por tecido fibroso e aumento da vascularização. Observou-se aumento da espessura da membrana sinovial e aumento do volume nuclear dos sinoviócitos. Nos animais dos grupos 3 e 4 houve aumento da espessura da membrana sinovial e presença de vilos. Os sinoviócitos dos animais do G4 encontravam-se vacuolizados.

Estes achados estão de acordo com Roy (1970) e Finsterbush e Friedman (1973), sempre associando hiperplasia sinovial, formação de vilos e proliferação celular na camada mais superficial em articulações imobilizadas. Os variados graus de degeneração observados nas células sinoviais resultaram em diminuição da produção de fluido sinovial e redução do suprimento nutricional à cartilagem. Conseqüentemente, a degeneração da cartilagem articular, observada ao longo das avaliações, deveu-se à atrofia da membrana sinovial determinando menor produção de líquido sinovial e ausência de bombeamento, uma vez que inibiu a difusão da menor quantidade de líquido sinovial que estava sendo produzida.

Também deve-se considerar que a cápsula articular e a membrana sinovial respondem à imobilização aumentando a sua espessura, que está funcionalmente associada à rigidez articular e a uma diminuição da amplitude de movimento. Com relação a estes aspectos, o exercício monitorado, sem impacto, como o preconizado, determinou melhorias como a evolução favorável da marcha.

$\mathrm{Na}$ avaliação das lâminas coradas por azul de toluidina, no G2, observou-se perda de metacromasia em relação ao controle, indicando perda dos componentes sulfatados da matriz da cartilagem articular. Entretanto, nos grupos 3 e 4, houve perda abrupta de metacromasia em áreas onde a cartilagem estava lesada. Esses resultados estão de acordo com Finsterbush e Friedman (1973) e Troyer (1975), que evidenciaram, em articulações imobilizadas, mudanças metabólicas com perda da coloração metacromática da matriz cartilaginosa previamente a qualquer mudança morfológica evidente à microscopia óptica. 

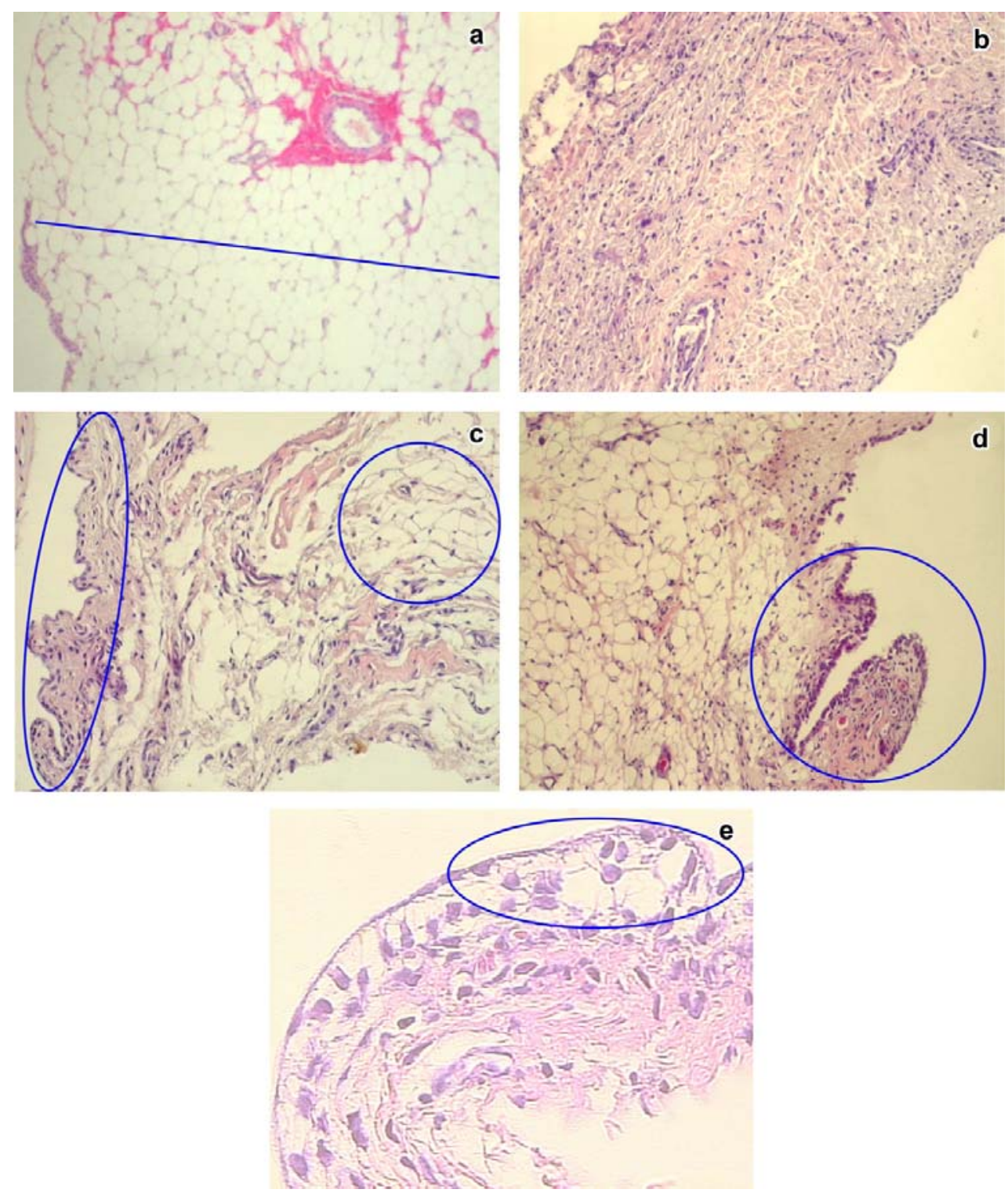

Figura 1. Cápsula articular após imobilização da articulação por 45 dias e remobilização por cinco semanas. a) animal do grupo controle, cápsula normal com grande quantidade de tecido adiposo (traço azul). b) animal do G2, substituição do tecido adiposo por tecido conjuntivo fibroso. c) animal do G3, substituição parcial do tecido adiposo (círculo) por tecido conjuntivo fibroso (elipse). d) animal do G3, espessamento da membrana sinovial e presença de vilos (círculo), (HE. 200X). e) animal do G4, vacuolização dos sinoviócitos (elipse), (HE. 400X).

Para Culav et al. (1999), o movimento articular é importante para a manutenção e a renovação dos proteoglicanos da cartilagem articular saudável, e a perda dos proteoglicanos após a imobilização é reversível com programas de remobilização articular. Portanto, os exercícios impostos aos animais dos grupos 3 e 4 permitiram aos condrócitos restaurar parcialmente os componentes da matriz, indicando que o movimento per si, sem sustentação do peso, contribuiu para restaurar os proteoglicanos da cartilagem articular.

No G2, observou-se aumento da população de condrócitos nas zonas superficial e intermediária, dispostos de forma irregular e não em colunas como na cartilagem normal (Fig. 2), que, segundo Hall (1963), em áreas de contato de articulações imobilizadas, as células apresentamse maiores que o normal e mais aglomeradas. 
Essa formação de grupos isógenos, para Piermattei e Flo (1999), indica processo de divisão celular em resposta ao estresse anormal, constituindo-se mecanismo natural de defesa da cartilagem.

No grupo 3, o aumento da população de condrócitos foi observado em oito animais, porém dois apresentaram diminuição da população de condrócitos com áreas de necrose na cartilagem articular (Fig. 2). Provavelmente, estas áreas estavam submetidas à sobrecarga por serem áreas de contato, enquanto, nos pacientes do grupo 4, observou-se aumento da população de condrócitos, que pode ser explicado pelos achados de Whiting e Zernicke (2001), segundo os quais, a atividade física prolongada em animais pode produzir hipertrofia dos condrócitos e aumento do número de células por unidade de cartilagem.

Ainda, com relação à cartilagem articular, em sete animais do grupo 2, nove do grupo 3 e seis do grupo 4, observou-se a presença do avanço da linha de maré, com aumento da espessura da cartilagem calcificada. Segundo Burr (2004), esse processo é uma adaptação à alteração da biomecânica da articulação e à natureza e distribuição de forças que são aplicadas na região superficial da cartilagem articular, adjacente ao espessamento.

Com a limitação prolongada do movimento, as superfícies articulares que não mantinham contato com a superfície oposta foram cobertas por tecido conjuntivo que teve origem na região da cápsula articular. Já nos pontos de contato entre o tecido conjuntivo e a cartilagem, formaram-se aderências transitórias e outras permanentes, que levaram a mudanças das células cartilaginosas. $\mathrm{O}$ aparecimento desse tecido conjuntivo e a conseqüente diminuição da espessura da cartilagem podem ter sido causados pela inadequada nutrição superficial e pela ausência do movimento. Em algumas regiões a cartilagem estava calcificada, não sendo mais observada a matriz e os condrócitos.

Pela avaliação do osso subcondral, observou-se em sete animais do G3 e três do G4, sempre na periferia da cartilagem e em locais semelhantes nos diferentes pacientes, tecido conjuntivo vascular preenchendo o espaço medular imediatamente adjacente à cartilagem, onde surgiam túneis vasculares que se dirigiam e penetravam dentro da camada profunda da cartilagem, destruindo o platô subcondral. Algumas evidências de reabsorção trabecular foram encontradas com a manifestação da atividade de osteoclastos.

O tecido de granulação observado no espaço medular subcondral pode refletir reação de cura em resposta ao dano limitado na cartilagem, com vasos sangüíneos medulares tentando suprir elementos de nutrição e reparo. Também refletem reparação de lesão no osso subcondral causada por esforços transmitidos através da cartilagem, que presumivelmente fatigam e fraturam a placa subcondral.

Em nove animais dos grupos 3 e 4 foram observadas áreas com aumento da espessura do osso subcondral (Fig. 3), em decorrência da perda da capacidade da cartilagem adjacente absorver estresse mecânico, sujeitando o osso subcondral a maior carga. Além do aumento da espessura, o osso perdeu característica trabecular, deformando menos diante das forças que são depositadas sobre a articulação.

Nove animais do G3 e cinco do G4 apresentaram achatamento da superfície articular do fêmur e da tíbia (Fig. 4). Como a integridade da cartilagem articular é dependente das propriedades mecânicas do seu leito subcondral, o espessamento do osso subcondral pode afetar a conformação articular, criando áreas de contato máximo embaixo da carga a que está sujeito.

Os animais do G3, após remoção da imobilização, iniciaram a deambulação sem qualquer preparação da articulação, que se encontrava pouco lubrificada, com nutrição deficiente, com alteração da mecânica articular pela perda dos componentes da matriz, espessamento e fibrose da cápsula articular e atrofia muscular. $\mathrm{O}$ resultado foi sobrecarga articular, alterações celulares da cartilagem, lesões severas com áreas de necrose, irregularidade das superfícies articulares e no osso subcondral aumento da espessura $\mathrm{e}$ reabsorção trabecular. 

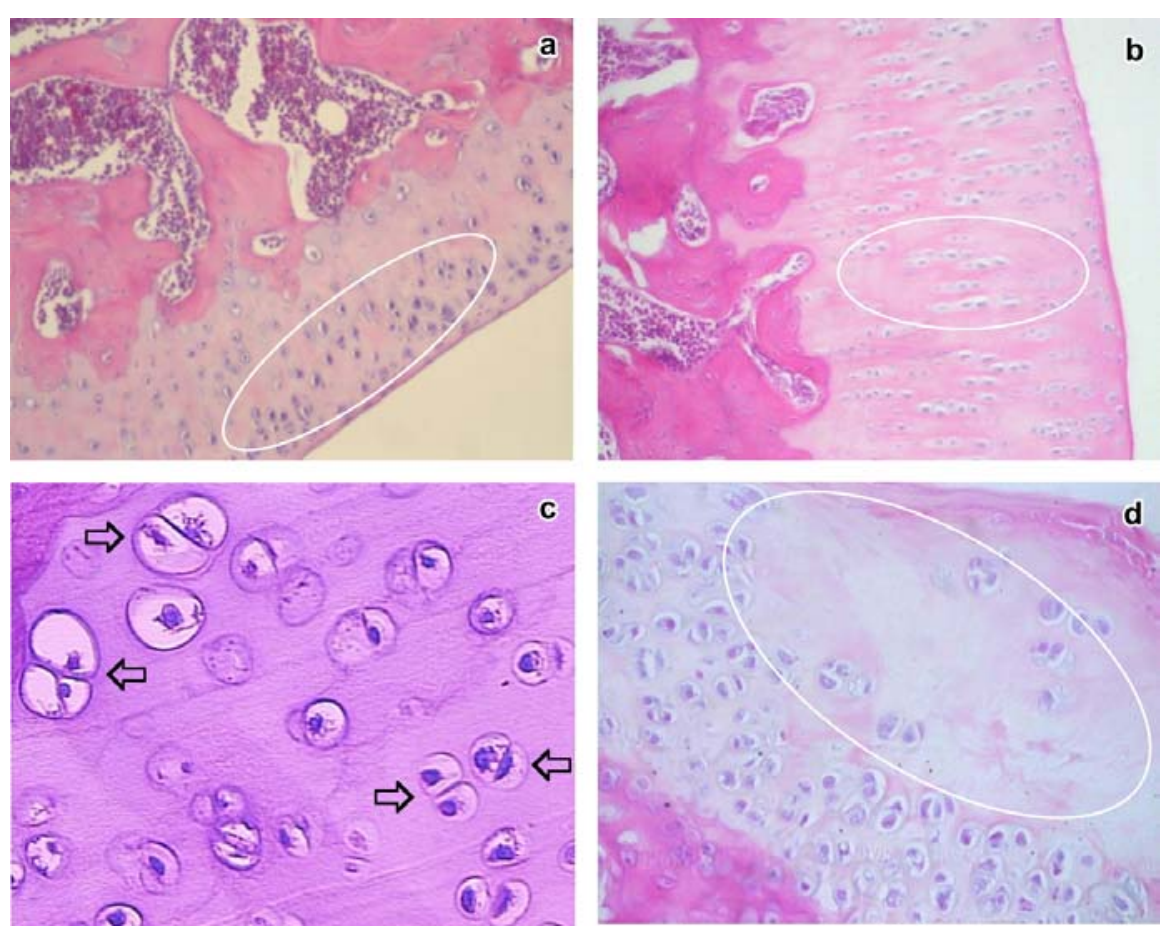

Figura 2. Aspectos celulares na cartilagem articular. a) animal do G2, aumento da população de condrócitos nas zonas superficial e intermediária (elipse), dispostos de forma irregular (HE. 200X). b) condrócitos disposto em colunas (elipse) em representante do G1 (HE. 200X). c) grupos isógenos (setas) em animal do G2 (HE. 1000X). d) diminuição da população de condrócitos em áreas de necrose (elipse) na cartilagem articular de animal do G3 (HE. 400X).
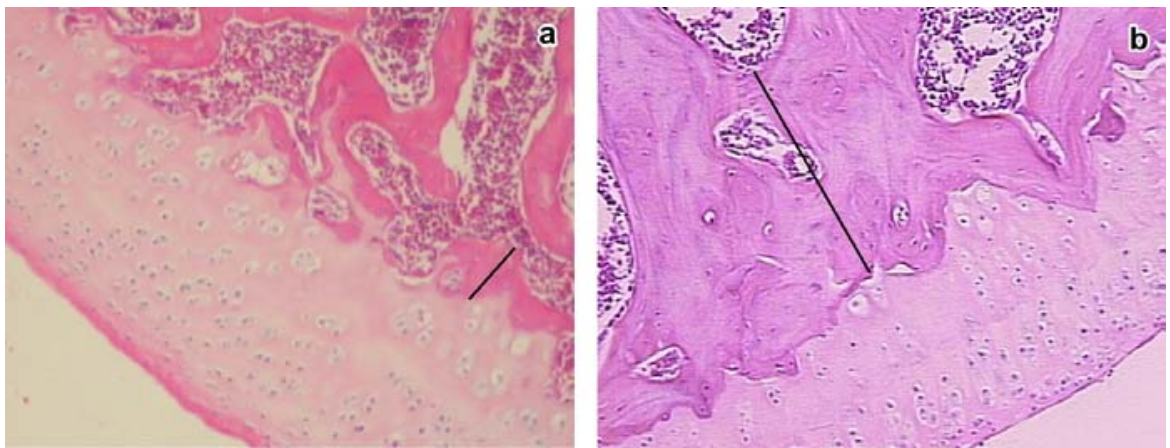

Figura 3. Imagem histológica demonstrando a superfície articular. a) espessura de trabécula do osso subcondral (traço preto) em animal do grupo-controle. b) espessura de trabécula do osso subcondral (traço preto) em animal do G3 (HE. 100X).
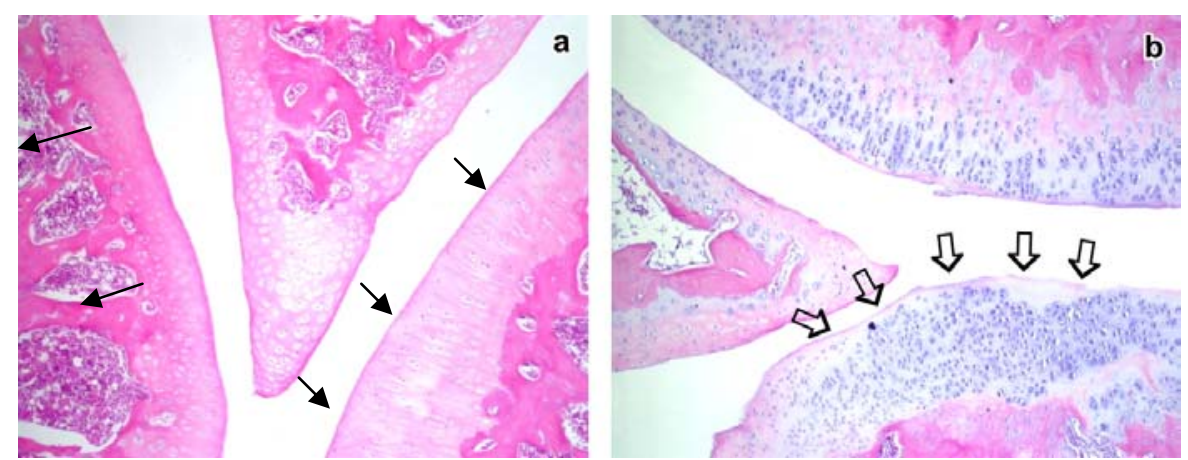

Figura 4. Imagem histológica demonstrando a superfície articular. a) regularidade da superfície articular normal (setas) em animal do grupo-controle. b) superfície articular irregular (setas) em animal do G3 (HE. 40X). 
Os animais do G4, que foram submetidos à natação, apesar de apresentarem algumas destas lesões, próprias do processo degenerativo imposto pela imobilização, demonstraram quadro menos severo. A natação determinou alívio do estresse sobre as articulações, permitindo a realização de movimentos em forças gravitacionais reduzidas, diminuindo as forças de compressão e os movimentos de friç̧ão. Isto facilitou a difusão do líquido sinovial, lubrificando e nutrindo a cartilagem, e permitindo o deslizamento das superfícies. A natação também promoveu o fortalecimento da musculatura envolvida na dinâmica articular, diminuindo a sobrecarga.

\section{CONCLUSÕES}

A imobilização da articulação femorotibiopatelar de ratos por 45 dias afeta negativamente a marcha e a amplitude articular, e tanto o exercício livre quanto o orientado influenciam positivamente no retorno das condições fisiológicas articulares determina aumento do número de condrócitos, aumento da espessura da cartilagem calcificada, irregularidade da superfície articular, proliferação de tecido conjuntivo no espaço intra-articular e aumento da espessura do osso subcondral e, nos animais imobilizados e submetidos à atividade livre e natação, determina menor número de alterações tanto na cartilagem articular quanto no osso subcondral, quando comparados com os animais que foram imobilizados e mantidos com atividade livre.

\section{REFERÊNCIAS BIBLIOGRÁFICAS}

BRANDT, K.D. Response of joint structures to inactivity and to reloading after immobilization. Arth. e Rheum., v.49, p.267-271, 2003.

BURR, D.B. Anatomy and physiology of the mineralized tissues: role in the pathogenesis of osteoarthrosis. Osteoarth. Cartil., v.10, p.1-11, 2004.

CAMPION, M. R. Os efeitos fisiológicos, terapêuticos e psicológicos da atividade aquática; Física básica: forma e densidade. In: __ Hidroterapia principios e prática, São Paulo: Manole, 2000. p. 3-4 e 14-22.
COLLINS, K. Efeitos térmicos. In: KITCHEN, S.; BAZIN, S. Eletroterapia de Clayton. 10.ed. São Paulo: Manole, p.89-104. 1998.

CULAV, E.M.; CLARK, C.H., MERRILEES, M.J. Connective tissues: matrix composition and its relevance to physical therapy. Phys. Ther., v.79, p.308-319, 1999.

EVANS, E.B.; EGGERS, G.W.N.; BUTLER, J.K. et al. Experimental immobilization and remobilization of rat knee joints. J. Bone Joint Surg., v.642A, p.737-58, 1960.

FINSTERBUSH, A.; FRIEDMAN, B. Early changes in immobilized rabbits knee joints: a light and electron microscopic study. Clin. Orthop., v.92, p.305-19, 1973.

HALL, M.C. Cartilage changes after experimental immobilization of the joint of the young rat. J. Bone Joint Surg., v.45A, p.36-44, 1963.

LEROUX, M.A.; CHEUNGT, H.S.; BAU, J.L. et al. Altered mechanics and histomorphometry of canine tibial cartilage following joint immobilization. Osteoarth. Cartil., v.9, p.633-640, 2001.

NARMONEVA, D.A.; CHEUNG, H.S.; WANG, J.Y. et al. Altered swelling behavior of femoral cartilage following joint immobilization in a canine model. $J$. Orthop. Res., v.20, p.83-91, 2002.

PIERMATTEI, D.L.; FLO, G.L. Articulações. In Manual de ortopedia e tratamento das fraturas dos pequenos animais. São Paulo: Manole, 1999. p.161176.

ROY, S. Ultrastructure of articular cartilage in experimental immobilization. Ann. Rheum. Dis., v.29, p.634-642, 1970.

SALTER, R.B. Os princípios gerais e métodos específicos do tratamento músculo-esquelético, In: Distúrbios e lesões do sistema músculo-esquelético. 2. Rio de Janeiro: Medsi, 1985. p.73-95.

THAXTER, T.H.; MANN, R.A.; ANDERSON, C.E. Degeneration of immobilized knee joints in rats. $J$. Bone Joint Surg., v.47A, p.567-85, 1965.

TROYER, H. The effect of short-term immoblization on the rabbit knee joint cartilage. A histochemical study. Clin. Orthop., v.107, p.249-257, 1975.

WHITING, W.C.; ZERNICKE, R.F. Biomecânica e adaptação dos tecidos, In: __ Biomecânica da lesão musculoesquelética. Rio de Janeiro: Guanabara Koogan, 2001. p.83-105. 